\title{
A EXTENSÃO UNIVERSITÁRIA E AS POSSIBILIDADES ADVINDAS PELO PROJETO “TECENDO A CONVIVÊNCIA” NA EXTENSÃO NASJEPI/UEPG
}

University extension and the possibilities arising from the project "Weaving the coexistence" in the extension NASJEPI/UEPG

\section{Simone Cristina Campos ${ }^{1}$ Thais Cristina Santos ${ }^{2}$}

RESUMO: O presente trabalho está centrado na importância da convivência social e familiar para o idoso, prevista na PNI e Estatuto do Idoso, e a dificuldade de se realizar atividades com grupos de convivência em tempo de pandemia. Destacando que, respeitando as orientações do Ministério da Saúde, mantendo o isolamento social é possível contribuir com a garantia desse direito, bem como, na proposição de uma atividade que preencha o vazio causado pelo isolamento e coloque a pessoa idosa em atividade motora, mental, cognitiva e, por que não? Se relacionando remotamente com as colegas do grupo, mantendo e fortalecendo os vínculos criados. Como processo metodológico, foi realizado um diagnóstico social, bem como parcerias para compra dos materiais. Ainda, foi distribuído kits contendo novelos de lã, agulha e manual de instrução para confecção dos quadradinhos de tricot ou crochê, com a finalidade de montar uma almofada onde todas participaram da confecção criando a "almofada da amizade". Como resultados, destacam-se a montagem de vinte e cinco almofadas as quais foram entregues as idosas. Quanto ao convívio social remoto, destaca-se relatos de sentimento de felicidade, participação e pertencimento.

Palavras-chave: Pessoa Idosa. Amizade. Convivência. Serviço Social. Dignidade Humana.

ABSTRACT: This work is focused on the importance of social and family life for people, foreseen in the PNI and in the Elderly Statute, making it difficult to carry out activities with groups of people in times of pandemic. Emphasizing that, respecting the guidelines of the Ministry of Health, maintaining social isolation, it is possible to contribute to the guarantee of openness, as well as, to the proposition of an activity that predefines or empties, provokes the isolation of hair and places people with motor, mental, cognitive and, why not? interacting remotely with colleagues in the group, maintaining and strengthening the bonds that were raised. As a methodological process, a social diagnosis was carried out, in partnership with the acquisition of two materials. In addition, kits containing needle soap and instruction manuals were distributed to make two squares of knitting or crochet, with the purpose of assembling a pillow where everyone participates in the

\footnotetext{
${ }^{1}$ Acadêmica no curso de bacharel em Serviço Social pela Universidade Estadual de Ponta Grossa- UEPG. Estagiária no projeto de extensão NASJEPI (UEPG). Ponta Grossa/PR. E-mail: simonecfontoura@hotmail.com.

${ }^{2}$ Professora Colaboradora no Curso de Bacharel em Serviço Social pela Universidade Estadual de Ponta Grossa- UEPG. Mestre em Ciências Sociais Aplicadas (UEPG). Ponta Grossa/PR. E-mail: thais.pluskota@gmail.com.
} 
making by lifting the "friendship pillow". As a result, we highlight an assembly of twenty-five pillows, such as which were delivered as elderly. As for a remote social confrontation, it highlights stories of feelings of happiness, participation and belonging.

Keywords: Elderly person. Friendship. Coexistence. Social service. Human dignity.

\section{INTRODUÇÃO}

A equipe de professores e estagiários do NASJEPI vem trabalhando desde 2012, ano de sua criação como projeto de extensão na UEPG (Universidade Estadual de Ponta Grossa), com as pessoas idosas da cidade, desde então vem observando um amadurecimento tanto na sociedade quanto na gestão pública, em enxergar a pessoa idosa como um ser de direito, merecedor de respeito e atenção.

Pensando no bem estar da pessoa idosa, através da disciplina de Estágio I, foi planejado e executado um projeto de intervenção que teve justamente a finalidade de discutir sobre a importância em garantir o direito à convivência e ao vínculo social e comunitário.

Direito este, que devido a pandemia, tornou-se desafio ainda maio, considerando, que muitos idosos, já se encontravam em processo de isolamento e distanciamento social, devido aos próprios estigmas sociais devido a sua idade. Desta forma, o NASJEPI/UEPG, por meio do Projeto Tecendo

a Convivência, buscou fortalecer os vínculos relacionais estabelecidos entre as participantes na convivência em grupo, promovendo a interação, o estreitamento das relações interpessoais, o respeito, a empatia e a reflexão sobre o sentido de pertencimento social.

Por meio da ação-reflexão-ação, foi proposto às idosas do Centro de Convivência "Idosas em Ação" a realização de uma atividade manual denominada - Quadradinhos do amor - consistindo na confecção de quadradinhos de lã em tricô ou crochê, que serviriam de materiais para a confecção de almofadas para as próprias idosas. Ao final, cada quadrado foi utilizado para a confecção de uma almofada denominada de "Almofada da Amizade".

Por analogia, se buscou com que as idosas o processo reflexivo quanto a importância dos vínculos de amizade, da interação e da importância de cada idosa, vem como de sua contribuição para a convivência no grupo. Foram confeccionadas 25 almofadas, cada uma contendo pelo menos um quadradinho de cada participante, as quais foram entregues a cada uma das idosas. Pelos relatos obtidos, se verificou que os vínculos entre as participantes foram mantidos e fortalecidos, elas 
interagiram via WhatsApp, estreitaram a amizade, desenvolveram suas habilidades pessoais e teceram a convivência interagindo socialmente e estreitando os vínculos relacionais.

\section{A extensão universitária e sua importância para a construção do conhecimento}

Segundo Iamamoto (2000, apud Rocha et al 2011, p. 3) “a extensão é um processo educativo, cultural e científico que articula a universidade com as necessidades dos segmentos majoritários da população". Como podemos perceber é através dos projetos de extensão que possibilita os acadêmicos a relacionar a teoria com a prática, além de poder ter contado com o público-alvo do projeto.

Na Universidade Estadual de Ponta Grossa (UEPG), os projetos de extensão têm origem em 1971, sendo voltado para levar conhecimento para as comunidades no município através de alguns cursos ofertados de forma gratuita para todos que tenham interesse (PROEX, 2019).

Segundo a Pró Reitoria de Extensão e Assuntos Culturais (PROEX, 2019), no ano de 1980 os projetos de extensão apresentaram-se como uma forma de articular a pesquisa com o ensino dentro da universidade, ou seja, permitindo aos acadêmicos da universidade a possibilidade de contato com a comunidade, realizando assim a práxis através dos projetos de extensão. Temos que a práxis social

como qualquer ato social, é uma decisão entre alternativas efetuada pelo indivíduo singular, que faz escolhas acerca de propósitos futuros visados. Porém, não faz escolhas independentes das pressões que as necessidades sociais exercem sobre os indivíduos singulares, interferindo nos rumos e orientaç̃̃es de suas decisões (IAMAMOTO, 20II, p. 254).

O projeto de extensão, por sua vez é considerado um conjunto de ações extensionistas, de origem educativa, cultural, científica e técnica, sugeridos por docentes e técnicos de nível superior, sendo indispensável a participação de discentes que trate de questões sociais relevantes.

Desde então, passa a existir como descrito por (IAMAMOTO, 20II, p 254) um "tripé" dentro da universidade, sendo estes: ensino, pesquisa e extensão. É através desse tripé que são articuladas estas três áreas, capacitando e proporcionando um maior aprendizado para o acadêmico, e para as demais pessoas envolvidas.

Segundo Iamamoto (20oo, apud ROCHA et al 20II, p.3) “a extensão é um processo educativo, cultural e científico que articula a universidade com as necessidades dos segmentos majoritários da população". Surgiu com o Decreto Federal no 1985, de Ir de abril de 1931, foi descrito como atividade de extensão a realização de cursos e conferências que traziam como objetivo a transmissão de conhecimentos que fossem importantes a vida individual e coletiva; mas também a apresentação de 
soluções para os compromissos sociais". Logo, é através dos projetos de extensão que possibilitou o relacionamento da teoria e da prática aos acadêmicos e a intervenção social junto à comunidade e suas demandas.

Desta forma, compreendendo a importância do projeto de extensão, e o grande número de demandas referente à falta de conhecimento sobre os direitos das pessoas idosa previsto no Estatuto do Idoso, que surgiu em fevereiro de zorl o projeto de extensão Núcleo de Assistência Social e Jurídica e de Estudo da Pessoa Idosa (NASJEPI).

\section{I.I NASJEPI e as possibilidades de intervenção no serviço social}

Atualmente o Núcleo de Assistência Social e Jurídica e de Estudo da Pessoa Idosa (NASJEPI) está localizado na Praça Santos Andrade, or na Universidade Estadual de Ponta Grossa - UEPG, campus central. Como função principal o NASJEPI busca realizar orientação a população em geral sobre os direitos estabelecidos no Estatuto do Idoso de 2003, com atividades de dinâmicas, palestras, recreativas, panfletagem, oficinas, capacitações, de forma didática e dinâmica, para que os idosos se apropriem do Estatuto do Idoso e a sociedade civil tomem conhecimento do mesmo, das leis de proteção da pessoa idosa, com isso proporcionando aos idosos um envelhecimento digno, com respeito, atendendo em todas as suas necessidades.

À equipe de Serviço Social no projeto de extensão, cabe propiciar e desenvolver ações voltadas para a melhoria da qualidade de vida dos usuários do serviço colocando em prática os conhecimentos teóricos metodológicos, amparados pelo código de ética da profissão, a partir do olhar crítico perante a realidade das pessoas idosas, sempre priorizando a defesa dos direitos como expressa o Estatuto do Idoso, como também, dar suporte técnico aos profissionais que trabalham diretamente com as pessoas idosas dos grupos de convivência.

No decorrer das atividades desenvolvidas pela equipe de Serviço Social do Núcleo, observou-se a fragilidade em diversos setores que influenciam na qualidade de vida da população de pessoas idosas e acompanhadas pelo Núcleo na cidade de Ponta Grossa, demandando um trabalho realizado em parceria interprofissional, contando com a colaboração de profissionais de várias áreas para levar o conhecimento para chamar a atenção da pessoa idosa do direito mais importante que é o de envelhecer com dignidade.

A população atendida pelas Assistentes Sociais é de forma indireta, são pessoas com mais de 60 anos, que participam dos Grupos e Centros de Convivência de idosos, CRAS. O número de 
pessoas que são atendidas varia de ano para ano e de atividade a ser desenvolvida, pois por se tratar de um projeto de extensão e de não trabalhar diretamente com a população alvo, faz com que mude os objetivos e a população especifica a ser trabalhada. Contudo atualmente são atendidos dois grupos de convivência, num total de 6o pessoas idosas nos grupos do SOS e SESC na cidade de Ponta Grossa.

Devido ao momento atípico em que estamos vivendo, de pandemia, onde o isolamento social se faz necessário, e a população atendida pelo NASJEPI é a população alvo do coronavirus, essa prestação de serviço se apresenta de forma remota, preservando assim tanto as idosas (públicoalvo), como os acadêmicos.

\subsection{Grupo de convivência "idosos em ação" do SOS (serviço de obras sociais) de Ponta Grossa}

O Serviço de Obras Sociais de Ponta Grossa - SOS, é uma associação civil, de natureza beneficente e filantrópica, sem fins lucrativos, de caráter educacional, cultural e de assistência social, fundado no dia 13 de junho de 1973, conforme o Estatuto Social Original; reconhecida de utilidade pública e inscrita no Conselho Municipal de Assistência Social em novembro de 1974 (SOS, 2013).

[...] na gestão do Sr. Luiz Gonzaga Pinto, que possuía a ideia de criar junto à Secretaria de Bem Estar Social um órgão que visasse a promoção e a recuperação dos homens junto a sociedade. Departamento de Ação Social da Secretaria Geral das Obras Municipais, registraram um total de 49 entidades na cidade de Ponta Grossa. Na oportunidade de criação do SOS, o departamento de Ação Social da Secretaria, organizou um cadastro geral do município, registrando um total de 49 entidades. (JUNIOR; SGABIERO; BOURGUIGNON, 1997, p.96).

Segundo a autora, Ponta Grossa foi considerada a Capital do Mendigo, devido ao fato de muitas pessoas carentes passarem por aqui em busca de melhores condições de vida e emprego, porém, não encontrando, acabava, por recorrer às obras de caridade e filantropia. A denominação de "Capital da Caridade", aparece citada num documento sobre Ponta Grossa, elaborado na administração de Luiz Carlos Zuk³ (1977 - 1982), cuja intenção era divulgar a estrutura da cidade em

\footnotetext{
${ }^{3}$ Luiz Carlos Stanislawczuk (Ponta Grossa, 23 de maio de 1944 - Balneário Camboriú, 28 de julho de 2016) foi um político brasileiro filiado ao Partido Democrático Trabalhista. Filho do imigrante polonês João Lira Stanislawczuk e Mercedez Vaz. Cursou Economia e Administração na Faculdade de Ciências Econômicas, Geografia na Universidade Estadual de Ponta Grossa e Direito na Faculdade de Direito de Curitiba. Foi vereador e prefeito de Ponta Grossa e deputado estadual do Paraná. Foi casado com Peggy Gutmann Stanislawczuk e juntos tiveram dois filhos. Morreu em Santa Catarina, no município de Balneário Camboriú, em 28 de julho de 2016 .
} 
diferentes setores, enaltecendo a vocação para o desenvolvimento industrial. No que se refere a assistência social, o documento diz o seguinte, "A cidade considerada Capital da Caridade, alicerça tal conceito numa série de entidades cujo desenvolvimento de atividades sobre perfeitamente este campo. Em destaque o SOS (ZUK, apud BOURGUIGNON, 1979, p.96). O SOS foi a primeira entidade estatal criada em Ponta Grossa, e o primeiro espaço oficial de intervenção da primeiraDama de Ponta Grossa, a partir de então, a presidência é seu cargo natural, ligado ao departamento de Ação Social da Secretaria de Obras Sociais, é uma entidade sem fins lucrativos, que há mais de 40 anos desenvolve importantes projetos sociais em nossa cidade com o objetivo de ampliar o acesso aos direitos sócio assistenciais e a melhoria na qualidade de vida. (HISTÓRICO - SOS, 1976 apud BOURGUIGNON, 1997, p.96).

Atualmente, ocupa um espaço cedido pela Fundação de Assistência Social de Ponta Grossa (FASPG), na Rua Joaquim Nabuco, 59. Possui um imóvel, localizado na Rua General Carneiro,III9 - no centro de Ponta Grossa, que por muitos anos abrigou a entidade, e hoje pela precariedade do prédio e sua estrutura física, não comporta a população atendida de 525 pessoas atendidas nos vários cursos profissionalizantes ofertados pela instituição. Possui 2 Assistentes Sociais, 2 administrativo, I motorista, 2 serviços gerais, 2 instrutoras de curso (corte e costura básica). Através de um convênio com a prefeitura municipal, que garante as despesas de pessoal e manutenção dos cursos profissionalizantes. Além dos cursos de formação profissional, recentemente, em 3I de julho de 2018 iniciaram um trabalho com as pessoas idosas, contando a participação de 32 pessoas no Grupo de convivência pera pessoa idosa (SOS-SERVIÇO DE OBRAS SOCIAIS DE PONTA GROSSA, 2013, 2013. p.I).

$\mathrm{Na}$ atual gestão, desenvolvem uma série de ações que visam muito mais que assistência imediata às famílias em situações de vulnerabilidades. A entidade atualmente executa dois importantes projetos: grupo de convivência com idosos, cursos profissionalizantes gratuitos a população, entre outros

Apresentamos detalhadamente as características do grupo de convivência do SOS da cidade de Ponta Grossa, onde atende 25 pessoas idosas do sexo feminino, a partir de 6o anos, com reuniões semanais das I4:0o h às I7:0o h, na sede do SOS, à Rua: General Carneiro, 743 - centro. Para melhor caracterizar este público, apresenta-se a seguir as características das idosas pertencentes ao grupo de convivência "Idosos em Ação" na cidade de Ponta Grossa/PR. Observe: 
Gráfico I- Idade das idosas participantes do projeto

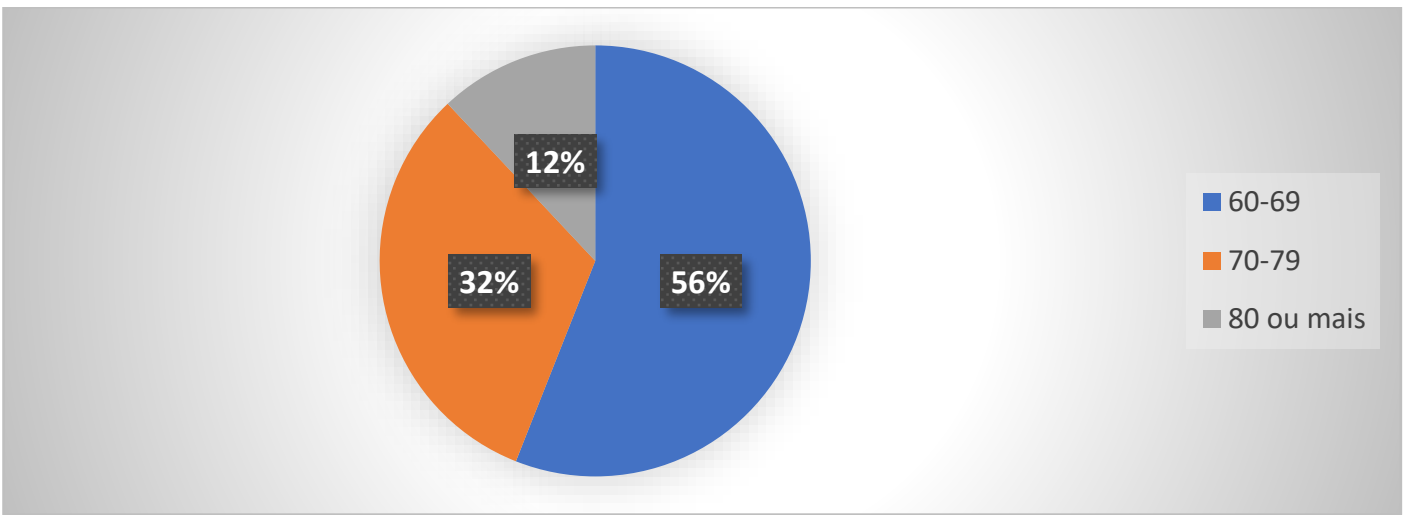

Nota: Organizada pela autora.

Observa-se que dentre o público que participará deste projeto a maioria estão entre sessenta a sessenta e nove anos. Desta forma, pode-se compreender, que em relação especificamente à idade (sem contar com relações de habilidade, saúde entre outro), todas as idosas possuem capacidade cognitiva para realização do projeto. O que demarca que o público se refere a idosas um grau de autonomia, o que possibilita a realização do presente projeto.

Por sua vez, vale destacar a situação civil das idosas, observe:

Gráfico 2- Estado Civil

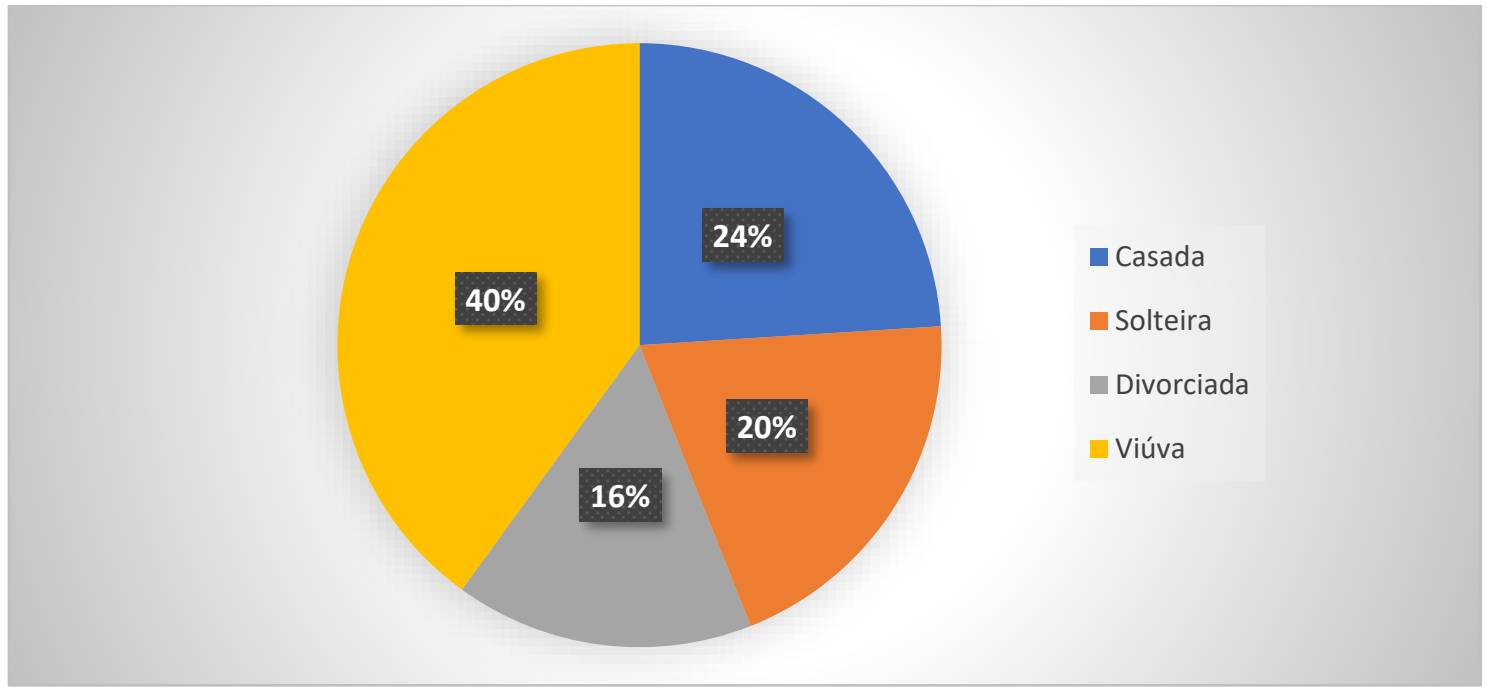

Nota: organizado pela autora 
Conforme o gráfico acima, a grande maioria das participantes do grupo de convivência Idosas em Ação são $40 \%$ viúvas, seguida por $24 \%$ casadas, $20 \%$ solteiras e $16 \%$ divorciadas. Nesse gráfico comprova-se a necessidade do ser humano em socializar-se, e a importância dos grupos de convivência, isto porque, $64 \%$ das idosas, moram ou sozinhas e apenas $16 \%$ moram com irmãs (destas, três imãs que moram juntas). Esta relação de moradia com outras pessoas, torna-se mais importante quando destacam-se sobre a relação de filhos das idosas, principalmente pelo fato de estarmos falando de mulheres dentro de uma sociedade patriarcal, ao qual, a responsabilidade ao longo da vida pelo cuidado familiar, torna-se da mulher, contudo, em seu processo de envelhecimento, esta realidade muda e quando a mulher necessita de cuidados, muitas vezes, não pode contar com a atenção dos filhos ou marido, por diversas situações.

Desta forma, destaca-se que dentre as idosas, $84 \%$ possuem filhos e i6\% não. Contudo, apenas duas das vinte e cinco das idosas convive com uma filha, as demais (segundo relato delas) nem ao menos as visitam, demarcando a urgência de projetos que direcionam atenção a pessoa idosa, para seu formate cimento emocional e de vínculo comunitário e institucional. Ainda, vale observar que relação é mais agravada quando percebemos a condição salarial das idosas. Assim em relação as condições de salário, observe:

Gráfico 3- Condição salarial

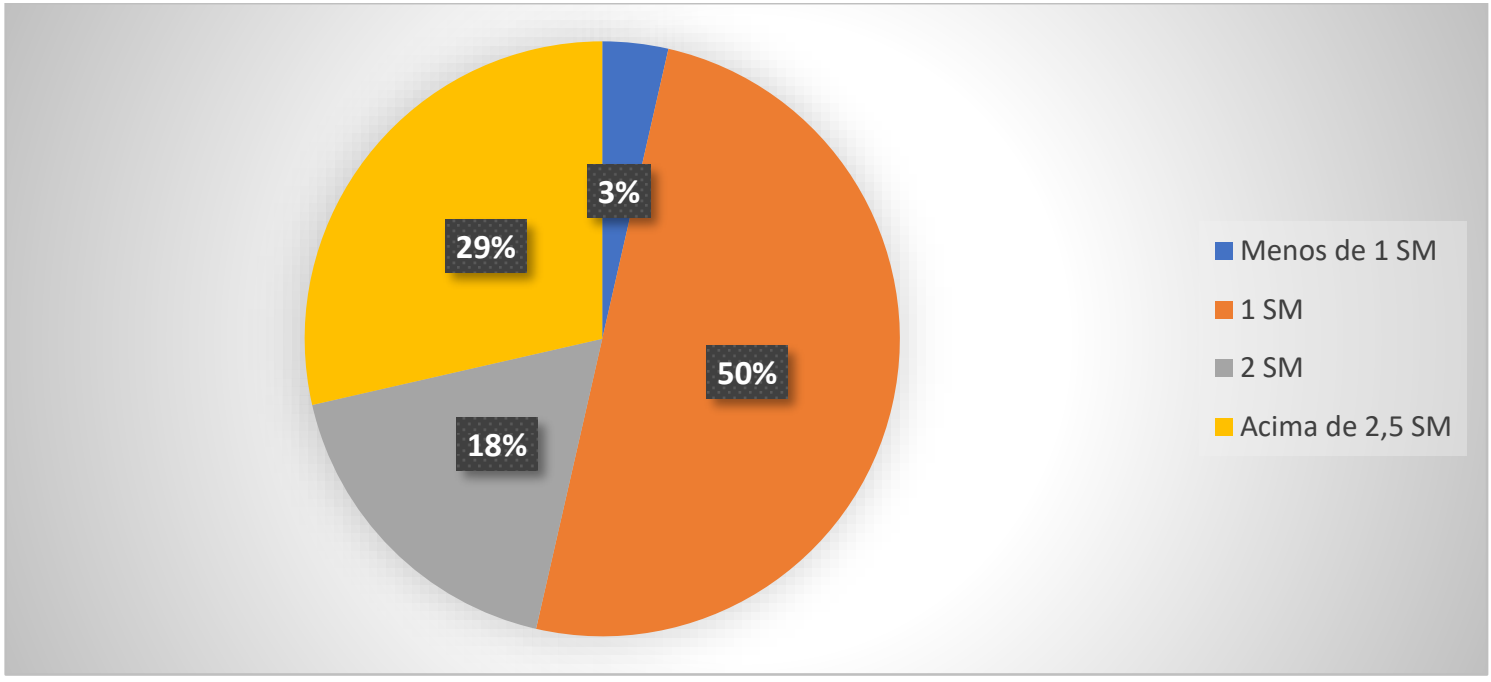

Nota: organizada pela autora 
Percebe-se neste gráfico que $29 \%$ das participantes do grupo possuem uma renda acima de 2,5 salários-mínimos mensal; $18 \%$ das participantes do grupo com renda de dois (2) salário-mínimo mensal; 50 \% das participantes do grupo de convivência com renda de um (I) salário-mínimo mensal e 3\% das participantes do grupo com renda inferior a i salário-mínimo mensal. O que demarca a necessidade atenção a vulnerabilidade social das idosas, compreendendo que existem diversos custos para a pessoa idosa, desde a moradia até aos cuidados com a saúde e cuidados pessoais, que com o processo de envelhecimento é acentuado.

Ainda em relação as condições sociais das idosas, vale ressaltar a condição de moradia, ao qual observou-se que $92 \%$ das pessoas idosas que participam do grupo de convivência possuem casa própria, em detrimento de apenas $8 \%$ que residem em casa alugada. Ainda, vale destacar que dentre as idosas, ainda, $32 \%$ relataram estar ativamente no mercado de trabalho.

Assim, em relação as atividades laborais, destacamos as idosas que trabalham como: mensalista, diarista, instrutora de arte, zeladora, cuidadora de idosos, zeladora e operadora de produção. Desta forma pode-se observar o público ao qual o presente projeto pretende alcançar.

\section{I.3 Desafios e perspectivas durante os dois semestres de 2020}

Todas as atividades realizadas pelas equipes do NASJEPI e do Grupo de Convivência "Idosos em Ação" do SOS (Serviço de Obras Sociais) de Ponta Grossa até o outubro de 2020, foram planejadas visando facilitar de alguma forma o enfrentamento a essa pandemia e isolamento social, que trazem sentimentos e emoções intensos as todas as pessoas, principalmente aos idosos.

Ademais, enquanto equipe de Serviço Social no projeto, buscou alternativas no intuito de que não perder o vínculo que foi construído há mais de quatro anos, fortalecendo os nossos laços e vínculos enquanto programa e população assistida. Diante deste contexto, a equipe de serviço social, buscou adaptar-se para elaborar um projeto de intervenção que contemple não só os objetivos da disciplina de estágio II do $4^{\stackrel{0}{ }}$ ano do curso de Serviço Social; do NASJEPI como projeto de extensão; como também, incentivar a pessoa idosa a realizar atividades de lazer, como um trabalho manual, mesmo em casa, com orientações por WhatsApp, e aproveitando algumas visitas das Assistentes Sociais do SOS, no sentido de encaminhar a proposta da atividade para a participação das idosas no projeto de intervenção. 
Nesse sentido, sabendo do benefício que o artesanato $^{4}$ traz, não só como lazer, proporcionando distração, estimulando o cérebro, habilidades motoras, como também para a saúde. Planejou-se um projeto que contribuísse para o mantimento da mente mais ativa das idosas, compreendendo que as atividades cognitivas é a melhor maneira de exercitar o cérebro e, consequentemente, preservar a memória.

Destaca-se que uma pesquisa recente feita pela Universidade da Califórnia aponta que as atividades que envolvem o sistema cognitivo são as melhores quando o assunto é exercitar o cérebro e preservar a memória. Entre elas estão: a leitura, a escrita, os jogos e os trabalhos manuais como o artesanato e a pintura, são algumas das atividades que ativam a mente e descontração.

Por isso, a prática é recomendada para quem se encontra com mais de sessenta anos, principalmente aqueles que já estão perdendo a memória aos poucos. A arte estimula a criatividade, faz o idoso expor suas ideias e melhorar suas aptidões. Além disso, segundo pesquisa realizada pela Faculdade de Medicina da USP, os idosos que fazem tarefas simples como corte e costura, tricô, crochet, trabalhos em madeira ou colagens, estão menos propensos a apresentarem demência.

A proposta com projeto de intervenção, atividade solicitada pela disciplina de estágio do $4^{\circ}$ ano do curso de Serviço Social da UEPG, foi exatamente priorizando em manter o cérebro da pessoa idosa ativo, entendemos que realizar uma atividade manual, distrai, apura os sentidos, ativa a mente e deixa esse isolamento menos doloroso. Diante disso, denominamos o projeto como: "TECENDO A CONVIVÊNCIA", com a finalidade de mesmo com o distanciamento social necessário, dado o contexto de pandemia, os vínculos entre as participantes sejam mantidos e fortalecidos, estimulando o desenvolvimento de suas habilidades manuais para a realização de uma atividade que lhes proporcione participação e interação social.

Assim, atividades artesanais simples como corte, costura, pintura, crochê e tricô podem se tornar ótimas terapias para qualquer pessoa. Isso porque o artesanato ativa os canais sensoriais do indivíduo, fazendo com que eles tenham que usar a imaginação e a criatividade.

\footnotetext{
${ }^{4}$ A leitura, escrita, jogos e trabalhos manuais como o artesanato e a pintura, são algumas das atividades de artesanato que ajudam a desenvolver as funções cognitivas, ativam a mente.
} 


\section{I.4 Tecendo convivências}

O projeto de intervenção "Tecendo a Convivência", foi elaborado justamente para que as idosas realizem uma atividade manual, onde seria confeccionado quadradinhos de crochet ou tricot com a intenção de transmitir amor e positividade por meio de linhas e fios. Uma atitude singela e repleta de significados que representa esse trabalho, que poderiam transmitir carinho em formas de quadrados de crochê.

Sua finalidade, era que aos poucos, cada nó em lã transitasse por diferentes mãos, na confecção desses quadradinhos, que ao final, seriam materiais, para a confecção de uma almofada para cada idosa. Destaca-se quem em sua maioria, pessoas que estão em situação de vulnerabilidade emocional e um pequeno gesto como esse, representa muito para quem está numa situação de isolamento social.

Logo, o projeto Tecendo Convivência teve como objetivo fortalecer os vínculos sociais estabelecidos na convivência em grupo, promovendo a interação, o estreitamento das relações interpessoais e a reflexão, a troca de experiências sobre a importância da convivência comunitária e social.

Desta forma, desenvolveu-se através da busca pela valorização do sentido de vida coletiva; da promoção da defesa e afirmação de direitos no desenvolvimento das capacidades das pessoas idosas; do desenvolvimento das atividades manuais, culturais, lazer, para que se sintam pertencente do contexto; do fomento da reflexão sobre convívio social e da realização da socialização dos produtos confeccionados, priorizando a convivência, a troca, o carinho.

Com o acelerado crescimento da população idosa, emerge desafios no que se refere ao atendimento as demandas e necessidades dessa parcela da população. Dentre estes está o direito à convivência familiar e comunitária garantido em lei (PNI e Estatuto do Idoso), o qual como tal "é uma prioridade que compreende a viabilização de formas alternativas de participação, ocupação e convívio da pessoa idosa." (OLIVEIRA et al, 2019, p.I) visando o seu bem-estar e protagonismo no âmbito da família, da comunidade e da sociedade, evitando assim o isolamento social e/ou a institucionalização.

Ressalta-se que

O convívio e relacionamento entre as pessoas, além de ser intrínseco à sua formação, ao seu desenvolvimento, e, portanto, ao próprio envelhecimento, são 
fatores imprescindíveis à maturação física e psíquica do ser humano; ao falar-se em convívio e relacionamento, há que se realçar que eles se apresentam em diversos setores da vida, tais como, na família, na comunidade, no trabalho, enfim, na sociedade em geral. (RODRIGUES, 2005, p.4)

Desta forma os grupos de convivência para pessoas idosas, (...) são uma forma de interação, inclusão social e uma maneira de resgatar a autonomia, de viver com dignidade e dentro do âmbito de ser e estar saudável. (WICHMANN et al, 2013, p.823) viabilizando um espaço de vivência coletiva na perspectiva do sentimento de pertencimento social e fortalecimento de vínculos.

Na política de assistência social a partir do SUAS - proteção social básica, é assegurado através do Serviço de Convivência e Fortalecimento de Vínculos - SCFV, o qual conforme a Tipificação Nacional dos Serviços Socioassistenciais, é realizado em grupos "de modo a garantir aquisições progressivas aos seus usuários, de acordo com o seu ciclo de vida (...)” (BRASIL, 2014, p.16)

Sendo assim, o Serviço de Obras Sociais, no desenvolvimento de suas ações oferta o SCFV para pessoas idosas através do Grupo Idosos em Ação visando assegurar o direito a convivência social realizando atividades físicas, culturais, recreativas, sociais e intelectuais no sentido "(...) da promoção do envelhecimento ativo, com o objetivo de preservar as capacidades e o potencial de desenvolvimento do indivíduo idoso, como preconiza a Organização Mundial da Saúde” (OMS, $2020, \mathrm{~s} / \mathrm{p})$.

A partir do exposto, ressalta-se que mesmo no contexto de pandemia, em que não é possível reunir as participantes do grupo já mencionado, de forma presencial, o trabalho com o grupo tem se mantido em parceria com o Projeto de Extensão Núcleo de assistência social, jurídica e de estudos sobre a pessoa idosa - NASJEPI da UEPG, de forma remota sendo desenvolvidas diferentes atividades para que as idosas continuem ativas, com autonomia, informadas, orientadas, interagindo, e mantendo os vínculos relacionais, uma vez que nos encontros semanais que ocorriam, a realização de atividades e dinâmicas diversas lhes permitiam a interação e a socialização.

Falar sobre a pessoa idosa em época de pandemia, remete discutir o processo de isolamento social, visto que ele se torna necessário para evirar a contaminação causada pelo Covid 19. Logo, como as pessoas em geral na medida do possível devem ficar em casa, especialmente os idosos por representarem o grupo de risco, algumas atividades são necessárias para fomentar o lazer.

De acordo com Mori e Silva (2010, p. 3) dessa forma, o lazer tem um papel importante, proporcionando que os idosos tenham uma vida mais descontraída, com mais socialização, podendo 
interagir com outras pessoas e culturas, participando da vida social, assumindo compromissos de modo enriquecedor e criativo com consequente inserção no meio sociocultural, já que segundo Pont Geis (2003) com o passar dos anos, a tendência é que os idosos se afastem de seus familiares, fiquem longe de seus entes queridos.

O lazer tem um papel significativo, pois, é possível de se realizar no tempo livre fora do tempo das obrigações, em que as pessoas podem se expressar, sentirem prazer, utilizarem-se de sua criatividade para se divertirem, descansarem e se desenvolverem e que pode agregar sujeitos com desejos e necessidades semelhantes, num mesmo ambiente (BRAMANTE, 1998). Sendo assim, tem relevância para as pessoas idosas no contexto.

Ainda sobre lazer DUMAZEDIER reafirma

[...]um conjunto de ocupações as quais o indivíduo pode entregar-se de livre vontade, seja para repousar, seja para divertir-se, recrear-se e entreter-se ou, ainda para desenvolver sua informação ou formação desinteressada, sua participação social voluntária ou sua livre capacidade criadora após livrar-se ou desembaraçarse das obrigações profissionais, familiares e sociais. (DUMAZEDIER, 200I, p. 132)

O lazer tem o poder de aproximar as pessoas, tem a capacidade de fazer descobrir novas coisas, de desenvolver a auto estima, suas habilidades motoras e seu sistema cognitivo.

Por esta razão acredita-se na necessidade de criar um projeto de intervenção que corresponda a estas demandas, principalmente quando direcionada a pessoa idosa, nesse contexto de isolamento social, onde torna mais difícil passar o tempo sem aqueles momentos de socialização.

A proposta da construção dos "quadradinhos do amor", foi pensada por ser uma atividade fácil, crochê ou tricô, onde todas tem o conhecimento, barata, não necessitam unicamente de locais especiais, podendo ser realizada nos próprios lares, mas sim, na essência que cada vivência pode ter para cada um, pois, como escreve Marcellino (2002, p. 08), "caracteriza o tipo de relação verificada entre o sujeito e a experiência vivida, basicamente a satisfação provocada pela atividade".

Nesse sentido na continuidade deste trabalho, para os meses de setembro à novembro, foi proposto o Projeto "Tecendo a Convivência" com a finalidade de mesmo com o distanciamento social necessário, dado o contexto de pandemia, os vínculos entre as participantes sejam mantidos e fortalecidos, estimulando o desenvolvimento de suas habilidades pessoais para a realização de uma atividade manual que lhes proporcione participação e interação social.

Destaca-se que, dentre as possibilidades, esse projeto oportunizou-se questões como socialização e sociabilidade, devido que cada parte do artesanato construído será compartilhado entre 
os participantes, e será confeccionada vinte e cinco almofadas, que também serão trocadas pelas participantes do projeto, simbolizando a amizade construída durante todo o período em que participam do grupo de convivência idosos em ação.

Assim, sociabilidade e socialização apesar de parecer a mesma coisa, têm significados diferentes. Sociabilidade, nada mais é do que a capacidade, a possibilidade ou até mesmo a inclinação em viver junto com outras pessoas, enquanto Socialização é a efetiva vivência com demais pessoas. Para tornar mais claro, simplifiquemos: A sociabilidade diz respeito a capacidade de ser sociável; sociabilidade é o nome dado para a possibilidade de socialização. Já a socialização é a vivência em sociedade, assimilando os hábitos, normas e costumes do grupo que participa.

\section{Metodologia do Projeto desenvolvido}

Por meio da ação-reflexão-ação, foi proposto para as idosas a realização de uma atividade manual denominada - Quadradinhos do amor - que consistiu na confecção de quadradinhos de lã em tricô ou crochê, conforme a habilidade que cada uma possuía, incentivando as mesmas para que ao realizar a atividade refletissem sobre o que cada quadradinho representaria no resultado final, ao qual foi, a confecção final de or almofada para cada participante e em relação ao propósito de tecer a convivência no grupo.

O procedimento ideal para execução deste trabalho, principalmente para o desenvolvimento das atividades psicomotoras, foi uma orientação oral e com um folheto explicativo, com o objetivo de orientar como deveria ser confeccionado os quadradinhos (tamanho, ponto, etc); qual o objetivo da confecção, isto é, de incentivar ao idoso a realizarem atividades, principalmente para ocupar seu tempo ocioso devido a pandemia. Para isso, contou-se com a parceria de duas Assistentes Sociais do SOS, as quais, levaram os kits contendo (lã, agulha e um modelo do quadradinho), e dar a explicação da atividade. A atividade contou com a participação de vinte e cinco idosas.

Desta forma, o projeto desenvolveu-se através das seguintes etapas: planejamento do projeto de intervenção; compra dos materiais a serem utilizados (patrocínio do Rotary Clube Sabará); separação dos kits para serem entregues; entrega dos kits para as vinte e cinco idosas; acompanhamento da confecção dos quadradinhos, via assistentes sociais do SOS, através do WhatsApp; encaminhamento para confecção das almofadas e finalização por meio da entrega das almofadas com os cartões, confeccionadas pelas colegas. 
Vale destacar que, para todos os procedimentos, foram tomados todos os cuidados sanitários necessários para preservação da saúde das idosas e dos participantes (acadêmica responsável e voluntários). Estes cuidados remetem-se a: uso de luvas; utilização de máscaras individuais; álcool Gel; distanciamento (não será adentrado às residências das idosas, o contato será pelo portão) e higienização dos materiais recolhidos (a mesma foi realizada, tanto no recolhimento dos quadrados quanto na entrega das almofadas prontas).

O procedimentos para construção das almofadas se deu através da confecção de 300 Quadradinhos do amor (20x20cm com 6 carreiras em crochê; Ioxıocm com 35 carreiras e 24 pontos); confecção de 25 almofadas ( $45 \mathrm{~cm}$ com o9 quadradinhos); entrega a cada idosa de 03 novelos de lã e or agulha (de tricô ou crochê); confecção de i6 quadradinhos de lã em crochê ou tricô (conforme sua habilidade); registro (foto) da execução (início, meio e fim) da atividade proposta; e avaliação com as participantes para expressar se foi ou não atingido o processo reflexivo quanto a atividade, este relato se deu através de um questionário de cinco perguntas e registro verbal (todo procedimento se deu através do termo livre esclarecido).

\section{RESULTADOS}

Destaca-se que o projeto pretendeu alcançar vinte e cinco idosas do projeto, contudo, ao longo do processo, uma idosa falecera. Desta forma, vinte e quatro idosa participaram assiduamente do projeto, confeccionando mais quadradinhos que o combinado. Observe a figura.

Figura 1. Quadradinho confeccionado pelas idosas participantes do projeto.

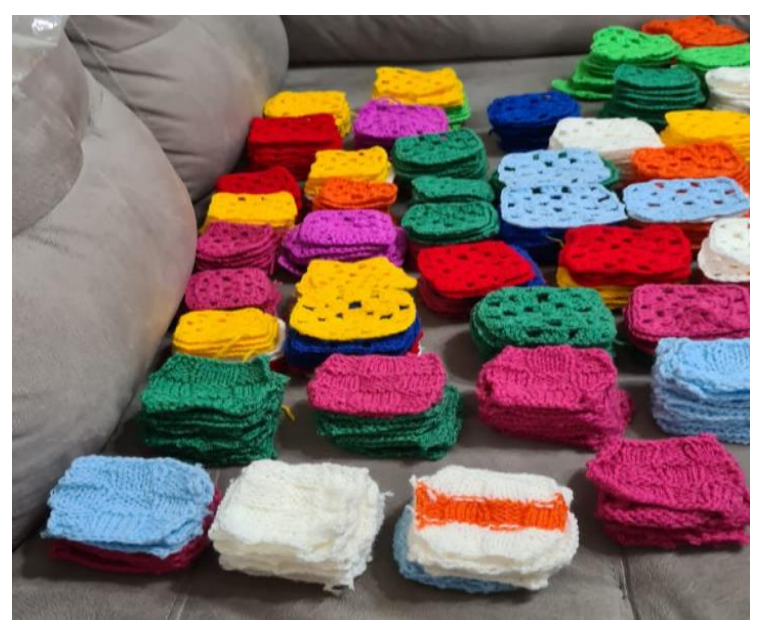

Nota: Projeto Tecendo a convivência 
Desta forma, foi possível construir almofadas maiores que o planejado para entregar as vinte e quatro idosas. Observe.

Figura 2 Almofadas prontas para entrega às idosas

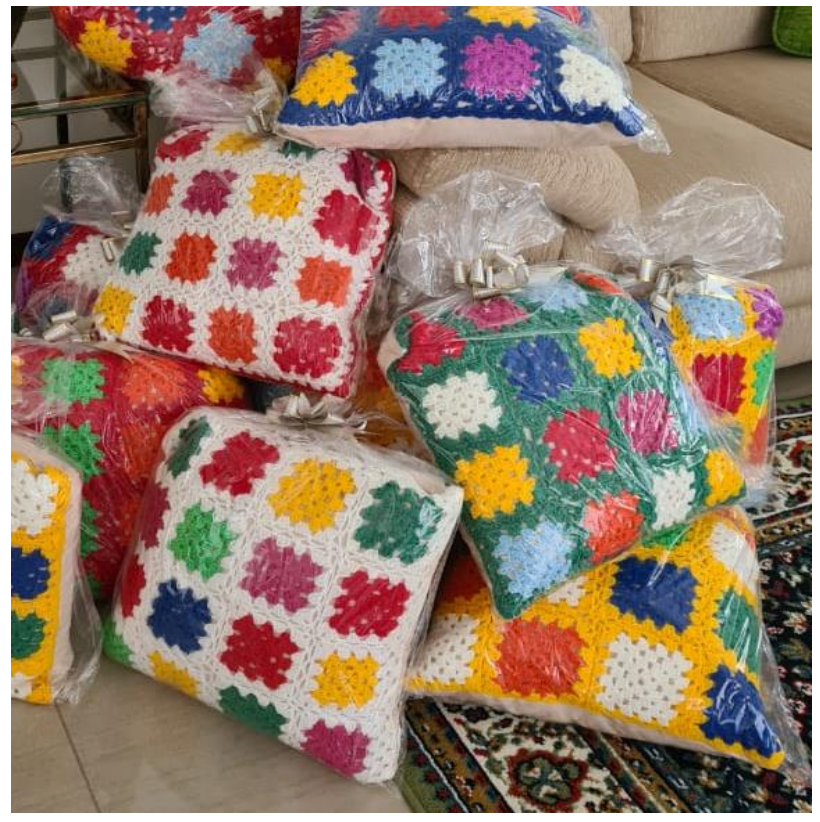

Nota: Projeto Tecendo a convivência.

Destaca-se que se tornou um desafio entre as participantes a construção do material. Contudo, através do incentivo a criatividade, a cooperação, a interação, foi possível alcançar o fortalecendo da amizade entre as idosas, contemplando o objetivo principal do projeto "tecendo a convivência.

\section{Considerações Finais}

É do impossível que se nutre a esperança! De um impossível viável, de um impossível que, como meta, horizonte, como estrela-guia, ilumina a luta e alimenta o otimismo da vontade para não desistir, para não acreditar no conformismo edulcorado que nos impõem os novos senhores do mundo. É do impossível que se nutre a política, construindo utopias de igualdade e justiça, de liberdade e solidariedade que se constroem nas lutas de hoje e se fortalecem nas lutas de amanhã 
(GENTILI; MCCOWAN, 2003, p. 27I). Desta forma, acredita-se na importância do fortalecimento de vínculos e dos direitos da pessoa idosa.

Com a sábia colocação dos autores acima citados, levando em consideração o momento em que estamos vivendo de pandemia do Covid $19^{5}$, onde o isolamento social mudou vários aspectos da rotina de todos. Acredita-se que todos e todas, especialmente a pessoa idosa merece atenção especial, afinal, são eles quem mais devem ser protegidos (as) devido a sua condição de risco. Seguindo essa orientação, os grupos de convivência ${ }^{3}$ suspenderam suas atividades presenciais respeitando o protocolo da OMS, provocando o afastamento das atividades cotidianas de socialização que os encontros nos grupos de convivência oferecem.

A partir deste questionamento, a equipe foi desafiada a pensar numa atividade, em que o direito ao envelhecimento ativo e saudável, e a convivência social e comunitária sejam priorizadas, e contemple o que a PNI e Estatuto do Idoso prevê, em seu artigo $3^{\circ}$

É obrigação da família, da comunidade, da sociedade e do Poder Público assegurar ao idoso, com absoluta prioridade, a efetivação do direito à vida, à saúde, à alimentação, à educação, à cultura, ao esporte, ao lazer, ao trabalho, à cidadania, à liberdade, à dignidade, ao respeito e à convivência familiar e comunitária. (BRASIL, 2003).

Diante dessa conjuntura, e contemplando o direito à convivência familiar e comunitária, como previstos no estatuto do idoso, é que foi realizado o projeto "TECENDO A CONVIVÊNCIA", com a finalidade de, mesmo com o distanciamento social necessário no contexto de pandemia, os vínculos entre as participantes e os integrantes do projeto sejam mantidos e fortalecidos, estimulando o desenvolvimento de suas habilidades, manuais, pessoais e criativa para a realização de uma atividade manual que lhes proporcione participação e interação social

Desta forma, diante de algumas dificuldades superadas, conseguiu-se executar satisfatoriamente o projeto de intervenção "Tecendo a convivência", contemplando plenamente o objetivo em fortalecer os vínculos sociais estabelecidos na convivência em grupo, promovendo a

\footnotetext{
5 Segundo o Ministério da Saúde, COVID-ıg é uma doença causada pelo coronavírus, denominado SARSCoV-2, que apresenta um espectro clínico variando de infecções assintomáticas a quadros graves. De acordo com a Organização Mundial de Saúde, a maioria (cerca de 80\%) dos pacientes com COVID-ı́ podem ser assintomáticos ou oligosintomáticos (poucos sintomas), e aproximadamente 20\% dos casos detectados requer atendimento hospitalar por apresentarem dificuldade respiratória, dos quais aproximadamente $5 \%$ podem necessitar de suporte ventilatório.
} 
interação, o estreitamento das relações interpessoais e a reflexão, a troca de experiências sobre a importância da convivência comunitária e social. O retorno dessa atividade por parte das idosas foi imediata e superou as expectativas, pois recebeu-se várias devolutivas durante o processo de satisfação, de troca, de aproximação (mesmo por chamada de vídeo) entre as idosas; sem perceber, foram desafiadas a cumprir essas atividades, pois as que não sabiam fazer, de alguma maneira conseguiram executar a atividade proposta dentro do tempo estipulado.

Essa atividade nos fez refletir sobre a importância da convivência social e familiar para o idoso e de que forma os grupos de convivência podem contribuir na garantia desse direito, bem como na promoção da longevidade aliada à qualidade de vida. De acordo com a Organização Mundial de Saúde (OMS), até 2025 o país ocupará o sexto lugar no ranking mundial de pessoas com mais de 60 anos. Sendo assim, a questão do envelhecimento sugere reflexões no sentido de que os governantes possam pensar e direcionar ações que deem conta das necessidades deste grupo específico, ou seja, é de extrema importância que se discuta formas de contribuir com o envelhecimento saudável e, acreditamos que a convivência social e familiar é um dos meios para isso.

Nesse sentido, a sociedade civil tem papel fundamental na reivindicação dos direitos sociais e na construção e efetivação das políticas públicas voltadas a população idosa. Assim, é de extrema importância que a sociedade conheça os direitos da pessoa idosa para respeitá-los e poder garantir sua efetivação.

Enquanto o Estado não assume a responsabilidade em elaborar políticas que contemplem essa população crescente no país, a sociedade civil se preocupa e tenta na medida do possível, com atividades pontuais e isoladas preencher esse espaço deixado pelo Estado no sentido de propor políticas para o atendimento a essas pessoas, que muitas vezes ficam a margem do convívio social e familiar.

\section{Financiamento:}

O presente projeto contou com a parceria do Rotary Club. Ponta Grossa, Paraná, Brasil.

\section{Referências bibliográficas}

BRASIL. Constituição da República Federativa do Brasil: promulgada em 5 de outubro de 1988. 4. ed. Brasília: Senado Federal, 1988.

BRASIL. Lei no $\mathbf{8 . 8 4 2}$ de 04 de janeiro de 1994. Política Nacional do Idoso. 
BRASIL. Lei no 10.741, de Io de outubro de 2003. Estatuto do Idoso. São Paulo: Sugestões literárias, 2003.

BRASIL. Portaria MDS no 134, de 28 de novembro de 2013. Dispõe sobre o Serviço de Convivência e Fortalecimento de Vínculos.

BRASIL. Código de Ética do Serviço Social: Lei 8.662, promulgada em 13 de março de 1993. Disponível em: 〈http://www.cfess.org.br/arquivos /CEP_CFESS -SITE.pdf〉 Acesso em: 03 Set 2020.

BRAMANTE, A. C. Lazer: concepções e significados. Licere, Belo Horizonte, vol.ı, n. I, p.o9-17, 1998.

COHEN, Ernesto; FRANCO, Rolando. Avaliação de Projetos Sociais. Rio de Janeiro, Ed. Vozes. I999.

DUMAZEDIER, Joffre. Lazer e cultura popular. São Paulo: Perspectiva, 1976. Disponível em https://ufsj.edu.br/portal-

repositorio/File/dcefs/Prof._Adalberto_Santos/Idumazedier_e_os_estudos_do_lazer_no_brasil_breve_trajetoria_historica_I2.pdf. Acesso em or de nov, de 2020 .

GENTILI, P.; MCCOWAN, T. (Org.). Reinventar a escola pública: política educacional para um novo Brasil. Petrópolis: Vozes, 2003.

MORI, G., SILVA L. F.S. Lazer na terceira idade: desenvolvimento humanoe qualidade de vida, 20io. Disponível em https://www.scielo.br/pdf/motriz/vi6n4/aisvi6n4.pdf. Acesso em 03/set/2020. Acesso em I2 de nov. de 2020.

MARCELLINO, N. C. Estudos do lazer: uma introdução.3 a ed. Campinas, SP. 2002.

OLIVEIRA, Maria Iolanda et al. GRUPO DE CONVIVÊNCIA: assegurando o direito da pessoa idosa. In Anais $7^{\circ}$ Congresso Paranaense de Assistentes Sociais.

OMS - Organização Mundial da Saúde. 2020. Disponível em https://www.bio .fiocruz.br/index.php/br/noticias/r763-o-que-e-uma-pandemia. Acesso em: 23 set 2020

PONT GEIS, P. Atividade Física na terceira idade: teoria e prática. $5^{\underline{a}}$ ed. Porto Alegre. 2003.

CASA DE REPOUSO EM FAMÍLIA. O artesanato na vida do idoso. Residencial em Família. Disponível em www.casaderepousoemfamilia.com.br Acesso em 25 de out. 2020

RODRIGUES, Oswaldo Peregrina. Estatuto do Idoso: Aspectos teóricos, práticos e polêmicos e o direito de família. Família e Dignidade Humana. Anais V Congresso Brasileiro de Direito de Família. Belo Horizonte: IBDFAM, 2005. Disponível em: http://www.ibdfam.org.br/publicacoes/anais/detalhes /714 V\%20Congresso\%2oBrasileiro\%20de\%20Direito\%2ode\%2oFam\%C3\%ADlia. Acesso em: 28 de set. 2020. 
WICHMANN, Francisca Maria Assmann; COUTO, Analie Nunes; AREOSA, Silvia Virgínia Coutinho; MONTANÉ́S, Maria Concepción Menéndez. Grupos de Convivência como suporte ao Idoso na melhoria da Saúde. Rev. Bras. Geriatr. Gerontol. Rio de Janeiro, 2013. 